and abnormal flavor nor induces severe cough. The occluder is small in size, with a definite occluding effect and good histocompatibility. Although the procedure reported here might violate the principle of keeping prosthetic material away from an infected field, this compromise might be appropriate in selected patients. This kind of procedure could be especially useful in the treatment of main bronchus pleural fistulas because it is not easy to shift contrast with a stent. Placement of the occluder through an existing chest tube tract might be developed as a better route because there is no need for general anesthesia and an endotracheal procedure.

\section{Conclusion}

Interventional closure of the PBPF with a specially designed doubleumbrella occluder is a safe, effective, and feasible approach. Because the number of cases is very limited, further studies are needed.

\section{References}

1. Vester SR, Faber LP, Kirtle CF. Bronchopleural fistula after stapled closure of bronchus. Ann Thorac Surg. 1991;52:1253-7.

2. Javadpour H, Sidhu P, Luke DA. Bronchopleural fistula after pneumonectomy. Ir J Med Sci. 2003;172:13-5.

3. Kiriyama M, Fujii Y, Yamakawa Y, et al. Endobronchial neodymium-yttrium-aluminum garnet laser for noninvasive closure of small proximal bronchopleural fistula after lung resection. Ann Thorac Surg. 2002;73:945-8.

4. Hirata T, Ogawa E, Takenaka K, et al. Endobronchial closure of postoperative bronchopleural fistula using vascular occluding coils and n-butyl-2-cyanoacrylate. Ann Thorac Surg. 2002;74:2174.

5. Li Qiang, Yang Xiaoming, Gong Shanshi, et al. Development of bronchial occlusive device made of NiTi memory alloy and its application for bronchial closure in dogs. Acad J Second Milit Med University. 2004;25:697-700.

\title{
Aneurysmal sternal bone cyst: A novel treatment method
}

\author{
Christopher T. Wartmann, MD, Carol D. Morris, MD, Malika Latmore, BS, and Raja M. Flores, MD, New York, NY
}

$\mathrm{T}$ he sternum is an uncommon location for aneurysmal bone cysts (ABCs). We present the case of a 25-yearold wrestler who was treated nonconventionally with curettage and bone graft substitute, negating the need for sternectomy with reconstruction.

\section{Clinical Summary}

This wrestler and athletic trainer was referred to an orthopedist after noting some persisting mild peristernal pain and swelling for 1 month's duration. The patient noted no other symptoms. A magnetic resonance imaging scan of his chest showed a $5.6-\mathrm{cm}$ multiloculated lesion within his lower sternum (Figure 1, B); a computed tomographic scan revealed a soft tissue mass causing lytic destruction of the posterior sternum (Figure 1, A). No other abnormalities were noted. Open biopsy confirmed the diagnosis of $\mathrm{ABC}$, both the solid and cystic types.

The patient underwent open surgical excision of the lesion. An elliptical incision was made over the sternum to incorporate the old incision, and the periosteum was split. An obvious defect in the anterior sternum was observed. The gross lesion was removed by using a combination of curets and pituitary rongeurs. Posteriorly,

From the Department of Surgery, Memorial Sloan-Kettering Cancer Center, New York, NY.

Received for publication March 23, 2007; accepted for publication April 12, 2007.

Address for reprints: Raja M. Flores, MD, Memorial Sloan-Kettering Cancer Center, 1275 York Ave, Room C-879, New York, NY 10021 (E-mail: floresr@mskcc.org).

J Thorac Cardiovasc Surg 2007;134:533-5

$0022-5223 / \$ 32.00$

Copyright $\odot 2007$ by The American Association for Thoracic Surgery doi:10.1016/j.jtcvs.2007.04.011 only the periosteum was intact (Figure 2,A). The defect was filled with an osteoinductive bone graft substitute. A $35 \times 34 \times 60-\mathrm{mm}$ mass was removed. The histopathology was consistent with an ABC. Follow-up imaging shows no evidence of recurrence at 2 years (Figure 2, $B$ ), and the patient has fully returned to wrestling with no complaints.

\section{Discussion}

$\mathrm{ABCs}$ are benign tumors of bone histologically composed of blood-filled cystic spaces separated by fibrous septa that contain an admixture of fibroblasts, variable numbers of osteoclast-type giant cells, and reactive woven bone. ABCs most frequently develop in the metaphyses of long bones and the posterior elements of vertebral bodies yet have been previously described arising in the pelvis and sternum. ${ }^{1}$ Approximately three quarters of cases are observed in persons younger than 20 years and rarely affect persons after 30 years of age. ${ }^{2}$ Radiographically, ABCs appear as a subperiosteal, poorly defined osteolysis elevating the periosteum and possibly leading to erosion of the cortex. Magnetic resonance imaging is helpful in showing the fluid levels within the cyst, as well as its internal septation. ${ }^{1}$

Although primary $\mathrm{ABCs}$ are rare lesions with an incidence of 0.14 per $100,000,{ }^{3}$ several treatment modalities exist, including surgical resection en bloc with the affected bone, curettage with bone grafting, selective arterial embolization, percutaneous injection of a fibrosing agent, and local radiation. Curettage with bone grafting is a widely accepted and published treatment modality in sites including the femur and pelvis. Although the sternum is an uncommon site, the mainstay of surgical treatment consists of a resection through partial sternectomy with reconstruction. The preservation of the posterior periosteum in this case coupled with the morbidity of partial sternectomy drove the authors to perform a sternum-sparing operation because $\mathrm{ABC}$ recurrence is evaded simply by means of complete mar- 


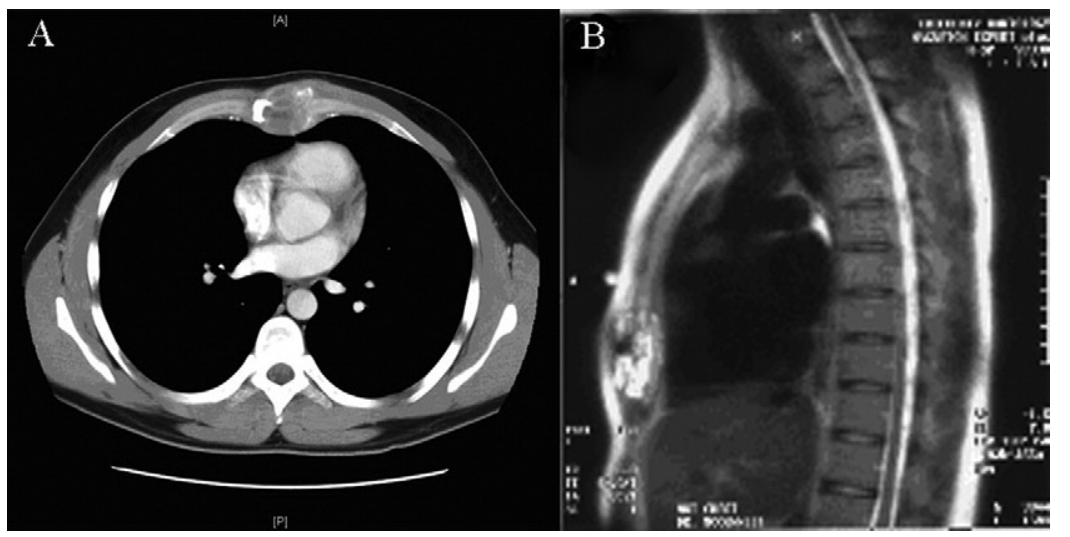

Figure 1. initial computed tomographic (A) and magnetic resonance imaging $(B)$ scans showing extensive involvement of the inferior sternum.

gin-free resection. To our knowledge, this is the first successful resection of a sternal $\mathrm{ABC}$ by means of curettage and grafting.

A multistudy review by Cottalorda and Gouin ${ }^{1}$ comparing different treatment modalities and their respective recurrence rates revealed that $77 \%$ of curettage/grafting procedures remain recurrence free compared with $95 \%$ using marginal or wide resection. However, several of the curettage procedures in this study were performed through a small opening, facilitating a higher risk of incomplete resection. Furthermore, in a study exploring the comorbidities experienced on chest wall reconstruction, Weyant and colleagues ${ }^{4}$ asserted that the presence of complications is directly proportional both to the size of the defect created in the surgical field and the absence of a true rigid chest wall reconstruction. Consequently, it would be preferable to avoid a chest wall defect altogether if possible, leading to a completely rigid reconstruction using the patient's existing bone matrix.

In summary, this young wrestler had his symptomatic sternal ABC successfully excised with a curettage and grafting procedure, allowing him to fully return to his activities. The authors believe that this method of treatment can serve as an alternative to unnecessary sternal resection in select patients with $\mathrm{ABCs}$, as well as producing comparable recurrence rates on use of proper and meticulous surgical technique.

\section{References}

1. Cottalorda J, Gouin F. Aneurysmal bone cyst. In: Chotel F, Goin F, editors. Benign osseous tumors. Paris: Expansion Scientifique Publications; 2005. p. 188-200.

2. Campanacci M, Bertoni F, Bacchini P. Aneurysmal bone cyst. In: Campanacci M, Bertoni F, Bacchini P, editors. Bone and soft tissue tumors. Vienna: Springer-Verlag; 1990. p. 725-51.

3. Leithner A, Windhager R, Lang S. Aneurysmal bone cyst: a populationbased epidemiologic study and literature review. Clin Orthop. 1999; 363:176-9.

4. Weyant MJ, Bains MS, Venkatraman E, Downey RJ, Park BJ, Flores RM, et al. Results of chest wall resection and reconstruction with and without rigid prosthesis. Ann Thorac Surg. 2006;81:279-85.

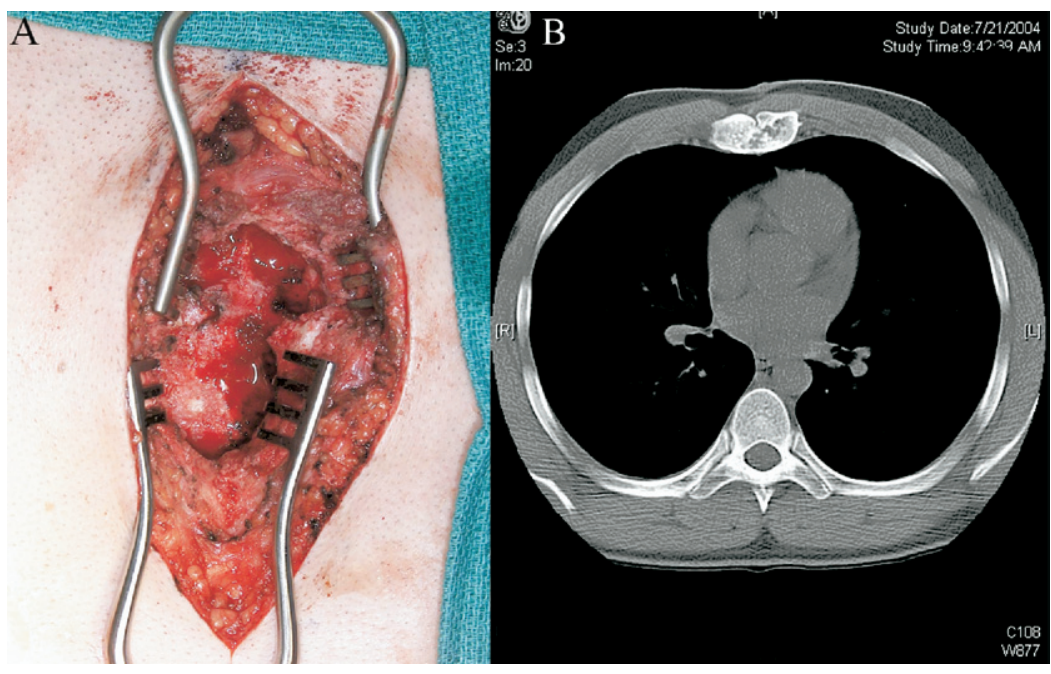

534 The Journal of Thoracic and Cardiovascular Surgery • August 2007
Figure 2. A, Surgical defect after excision with posterior periosteum intact. B, Follow-up computed tomographic scan at 18 months showing recurrence-free bony remodeling. 